\title{
Vaccination and rheumatoid arthritis
}

\section{J Sibilia, J F Maillefert}

\section{Induction of rheumatoid arthritis by vaccination against hepatitis B-myth or reality?}

$\mathrm{R}$ ecently, medical and public interest in the safety of vaccination, particularly against hepatitis $\mathrm{B}$, has been heightened by reports in medical journals and in the media of possible adverse effects, especially of suspected vaccination-induced autoimmune disorders. Although these suspected effects most commonly belong to the neurological area, a number of authors have published cases of rheumatic disease, notably rheumatoid arthritis (RA), following hepatitis $\mathrm{B}$ vaccination. ${ }^{1-10}$ This editorial does not aim to review the relationship between vaccination and autoimmune disorders, which has already been discussed in several recent and interesting papers, ${ }^{11-13}$ but to centre the discussion on the possible connection between hepatitis B vaccination and RA.

The rheumatic disorders described following hepatitis $\mathrm{B}$ vaccination are heterogeneous but can be divided into three groups. Firstly, transient conditions such as vasculitis, post-vaccinal arthritis or erythema nodosum might be due to the deposition of immune complexes containing viral antigen and antihepatitis B antibodies, as seen in some hepatitis B infections, or to hypersensitivity to components of the vaccine like thimesoral or yeast proteins. ${ }^{14}{ }^{15}$ Recently, the VAERS (Vaccination Adverse Events Reporting System) database (from July 1990 to August 1999) reported that hepatitis B vaccination was associated with a number of potentially serious arthritic adverse reactions, particularly in the adult female population (female/ male ratio $=4.45 / 1) .{ }^{16}$ Secondly, it was recently suggested that macrophagic myofasciitis might be induced by intramuscular injection of vaccines containing aluminium hydroxide such as hepatitis B vaccine. ${ }^{17}$ Thirdly, there are reports of the onset of chronic autoimmune disease and, in particular, of RA.

Several hypotheses can be put forward for the occurrence of RA after immunisation against hepatitis $\mathrm{B} .{ }^{11}(1)$ The relation between vaccination and disease might in fact be coincidental and this possibility will be discussed later. (2) Alternatively, the vaccination might induce specific forms of disease. There are, however, no apparent differences between postvaccinal and classical RA, which present alleles. ${ }^{9}$ similar clinical and laboratory characteristics. ${ }^{10}$ Moreover, as patients with post-vaccinal RA often develop joint erosions or periarticular osteoporosis and often require disease modifying antirheumatic drugs, the resemblance to classical RA does not favour this hypothesis.

(3) A more attractive view is that hepatitis $\mathrm{B}$ immunisation may trigger the onset of disease in subjects with underlying genetic and immunological susceptibility. Thus, some case reports describe the onset of RA following a first vaccine injection, with recurrence or worsening of the articular symptoms after a second injection. It is of interest to note that most patients with postvaccinal RA express HLA-DRl or HLADR4, or both. ${ }^{910}$ Furthermore, the patients described by Pope et al shared the HLA-DR $\beta 10301$ and HLA-DQ $\beta 10201$

\section{"A genetic susceptibility to RA may be activated by vaccination"}

Current thinking favours the theory that RA develops in susceptible subjects in response to environmental stimuli and among the possible stimuli, infection and vaccinal immunisation have been postulated as the most likely. ${ }^{18}$ An interesting case-control study of Harrison et al suggested that the frequency of prior immunisation (tetanus toxoid, influenza, and others) was higher among patients with inflammatory polyarthritis, including RA, than among age and sex matched controls. ${ }^{19}$ These authors also observed that inflammatory polyarthritis appearing after immunisation did not seem to differ from other forms of the disease. Ferrazzi et al described patients in whom hepatitis A vaccination was followed by a connective tissue disorder or spondyloarthropathy, ${ }^{20}$ and reports of rheumatic disease occurring after other vaccines have appeared..$^{21}$ The results of Harrison's study, the diverse vaccines implicated in postimmunisation polyarthritis, the variety of affections seen after hepatitis B vaccination and the resemblance between the post-vaccinal conditions and well characterised disorders support the hypothesis that immunisation, especially to hepatitis B, may activate underlying chronic inflammatory or autoimmune disease and, in particular, RA in susceptible subjects.

However, the cases have usually been presented in the form of case reports and only a few series have been reported. ${ }^{910}$ There are moreover no epidemiological data to support the idea that hepatitis B vaccination might induce rheumatic autoimmune disorders, especially RA. Consequently, we do not know whether there exists a causal or a coincidental relationship between RA and hepatitis B vaccination. The immunisation programmes have not shown any association between immunisation against hepatitis B and the occurrence of autoimmune disorders, including $\mathrm{RA}^{22-24}$ which suggests that there is no or only a very slight connection between the vaccination and these diseases. In addition, several recent epidemiological studies did not show any relationship between hepatitis B vaccination and multiple sclerosis, ${ }^{25}{ }^{26}$ systemic lupus erythematosus, or RA. ${ }^{27}$ One case-control study, conducted using the British General Practitioners Research Database (GPRD), included 2814 patients with RA and 27040 controls. Vaccination against hepatitis B had been performed in 52 patients and 449 controls, the odds ratio was 1.1 (95\% CI 0.8 to 1.4$)^{27}$ and a complementary subgroup analysis failed to detect any significant association between RA and hepatitis B immunisation. Hence the recent increase in published cases might simply be due to the universal immunisation programmes in which, for example, more than one third of the French population was vaccinated in the past few years. ${ }^{28}$

Thus, there are conflicting data with, on the one hand, negative results from immunisation programmes and epidemiological studies and, on the other hand, case reports which are sometimes very suggestive. These results might provide evidence to support the somewhat provoking hypothesis of the protective effect of infections and immunisations. ${ }^{13}$ In fact, the microbial environment can shape the immune response and, in particular, tolerance phenomena, which would explain why, in practice, immunisations against microbes may reduce the risk of the occurrence of autoimmune disorders. Nevertheless, in the case of existing autoimmune disease, a nonspecific immunisation might activate the inflammatory reaction, leading in RA to an exacerbation of the articular manifestations. Although further epidemiological studies will be necessary to clarify these phenomena, one may conclude at present that if hepatitis $B$ vaccination can trigger RA, it is an infrequent event. 
Hence we still require answers to several questions, such as "Do we need to stop the universal immunisation programmes?", or "Is it dangerous to vaccinate patients with RA against hepatitis B?" Because the immunisation programmes and epidemiological studies indicate that there is no or only a very slight association between hepatitis B vaccination and autoimmune or chronic inflammatory rheumatic disorders, the benefits of the vaccine probably outweigh the risks of possible side effects. Universal hepatitis B vaccination indeed significantly reduced the virus carrier and infection rates among children and adolescents in a hyperendemic area. ${ }^{29}$ In Italy, the annual incidence of acute hepatitis B virus infection decreased from 5.4 to $2.9 / 10^{5}$ inhabitants between 1990 and 1998 (and from 17.3 to $4.2 / 10$ in 15-24 year olds), suggesting that universal immunisation does reduce the incidence of infection. ${ }^{30}$ In France, it has been estimated that 3-29 cases of fulminans hepatitis and 12-147 cases of cirrhosis or hepatocellular carcinoma would be avoided in an fictive cohort of 800000 vaccinated 11 year old preadolescents, up until the age of $30 .^{28}$ Thus, in our opinion, universal immunisation has to go on.

There remains the question of hepatitis $B$ vaccination in some individual subjects, such as patients with RA. Before attempting to reply, one should recall that this matter has been raised for other vaccinations, notably agains influenza. ${ }^{31}{ }^{32}$ Different studies have shown that such immunisations induce no significant RA, apart from possibly certain exceptions like the vaccine against measles. ${ }^{33}$

The report of Elkayam et al in this issue of the Annals of the Rheumatic Diseases constitutes a first step in the reply to this question with respect to RA. In this study hepatitis B vaccination in patients with RA was not associated with any appreciable deterioration of the clinical or laboratory measures of disease activity. ${ }^{34}$ However, before claiming that immunisation against hepatitis B is safe in patients with RA, these reassuring results need to be confirmed in larger scale studies. In the meantime, vaccination should be proposed cautiously in selected cases, taking into account the individual risk of developing hepatitis $\mathrm{B}$ and the fact that the vaccine elicits a protective antibody response in only $66 \%$ of patients with RA. ${ }^{34}$

Ann Rheum Dis 2002;61:575-576

\section{Authors' affiliations}

J Sibilia, Department of Rheumatology, Strasbourg University Hospital, France J F Maillefert, Department of Rheumatology, Dijon University Hospital, France

Correspondence to: Dr J Sibilia, Department of Rheumatology, Hôpital Hautepierre, Avenue Molière, 67098 Strasbourg, France;

jean.sibilia@wanadoo.fr

\section{REFERENCES}

Hachulla $E$, Houvenagel E, Mingui A Vincent $G$, Laine A. Reactive arthritis after hepatitis $B$ vaccination. J Rheumatol 1990; 17:1250-1

2 Rogerson SJ, Nye FJ. Hepatitis B vaccine associated with erythema nodosum and polyarthritis. BM 1990:301:345

3 Biasi D, De Sandre G, Bambara LM, Carletto A, Caramaschi P, Zanoni G, et al. A new case of reactive arthritis after hepatitis $B$ vaccination. Clin Exp Rheumato 1993;11:215-20.

4 Vautier G, Carty JE. Acute seropositive heumatoid arthritis occurring after hepatitis $B$ vaccination. Br J Rheumatol 1994;33:991.

5 Gross K, Combe C, Krüger K, Schattenkirchner M. Arthritis after hepatitis B vaccination. Report of three cases. Scand J Rheumatol 1995;24:50-2

6 Aherne P, Collins M. Psoriatric arthropathy. Irish Med J 1995;88:72

7 Soubrier M, Dubost JJ, Bielsa C, Ristori JM, Bussière JL. Polyarthrite érosive déclenchée par une vaccination contre l'hépatite $B$. Presse Med 1997;26:75

8 Treves R, Lacoste L, Bontoux D, Pitrou E, Bertin P, Bonnet $C$. Polyarthrite nodulaire érosive déclenchée par une vaccination contre I'hépatite B. Presse Med 1997;26:670.

9 Pope JE, Stevens A, Howson W, Bell DA Rheumatoid arthritis linked to hepatitis $B$ vaccination. J Rheumatol 1998:25:1687-93.

10 Maillefert JF, Sibilia J, Toussirot E, Vignon E, Eschard JP, Lorcerie B, et al. Rheumatic disorders following hepatitis $B$ vaccination. Rheumatology (Oxford) 1999;38:978-83.

11 Shoenfeld Y, Aron-Maor A. Vaccination and autoimmunity - "vaccinosis": a dangerous liaison? J Autoimmun 2000; 14:1-10.

12 Chen RT, Pless R, DeStefano F. Epidemiology of autoimmune reactions induced by vaccination. J Autoimmun 2001;16:309-18.

13 Bach JF. Protective role of infections and vaccinations on autoimmune diseases. J Autoimmun 2001; 16:347-53.

14 Rietschel RL, Adams RM. Reactions to thimesoral in hepatitis B vaccines. Dermatol Clin 1990;8:161-4.

15 Brightman CAJ, Scadding GK, Dumbreck LA, Latchman Y, Brostoff J. Yeast-derived hepatitis $B$ vaccine and yeast sensitivity. Lancet 1989;i:903.

16 Geier DA, Geier MR. Hepatitis B vaccination and arthritic adverse reactions: a followup analysis of the Vaccine Adverse Events Reporting System (VAERS) database. Clin Exp Rheumatol 2002:20:119.

17 Guerardi RK, Coquet M, Cherin P, Belec L, Moretto P, Dreyfus PA, et al. Macrophagic myofasciitis lesions assess long-term persistence of vaccine-derived aluminium hydroxide in muscle. Brain 2001;124:1821-31

18 Symmons DPM, Chakravarty K. Can immunisation trigger rheumatoid arthritis? Ann Rheum Dis 1993;52:843-4.

19 Harrison BJ, Thomson W, Pepper L, Ollier WER, Chakravarty K, Barrett EM, et al. Patients who develop inflammatory polyarthritis (IP) after immunization are clinically indistinguishable from other patients with IP. Br J Rheumatol 1997;36:366-9.

20 Ferrazzi V, Jorgensen C, Sany J. Inflammatory joint disease after vaccination. A report of two cases. Rev Rhum (Engl Ed) 1997:64:227-32.

21 Maillefert JF, Tonolli-Serabian I, Cherasse A, Demoux AL, Piroth L, Tavernier C. Arthritis after combined vaccine against diphtheria, polyomyelitis, and tetanus toxoid. Clin Exp Rheumatol 2000;1 8:255-6.

22 Anonymous. Update: vaccine side effects, adverse reactions, contraindications, and precautions. Recommendations of the Advisory Committee on Immunization Practices (ACIP). MMWR 1996;45:1-35

23 McMahon BJ, Helminiak C, Wainwright RB, Bulkow L, Trimble BA, Wainwright K. Frequency of adverse reactions to hepatitis $B$ vaccine in 43,618 persons. Am J Med 1992;92:254-6.

24 Dobson S, Scheifele D, Bell A. Assessment of a universal, school-based hepatitis B vaccination program. JAMA 1995;274:1209-13

25 Ascherio A, Zhang SM, Hernan MA, Olek M, Coplan PM, Brodovicz K, et al. Hepatitis $B$ vaccination and the risk of multiple sclerosis. N Engl J Med 2001;344:327-23.

26 Confavreux C, Suissa S, Saddier $P$, Bourdès $V$, Vukusic S. Vaccinations and the risk of relapse in multiple sclerosis. $N$ Engl J Med 2001;344:319-26

27 Vaccination antihépatite B. Mise à jour des données et des études de pharmacovigilance. Février 2000. http://agmed.sante.gouv.fr/ pdf/6/vhbrap.pdf

28 Lévy-Bruhl D, Rebière I, Desenclos JC, Drucker J. Comparaison entre les risques des premières atteintes démyélinisantes centrales aiguës et les bénéfices de la vaccination contre l'hépatite B. Bulletin Epidémiologique Hebdomadaire 1999;(9):33-5.

29 Ni YH, Chang MH, Huang LM, Chen HL, Hsu HY, Chiu TY, et al. Hepatitis B virus infection in children and adolescents in a hyperendemic area: 15 years after mass hepatitis B vaccination. Ann Intern Med 2001;135:796-800.

30 Zanetti AR. Update on hepatitis B vaccination in Italy 10 years after its implementation. Vaccine 2001 19:2380-3.

31 Chalmers A, Scheifele D, Patterson C, Williams D, Weber J, Shuckett R, et al. Immunization of patients with rheumatoid arthritis against influenza: a study of vaccine safety and immunogenicity. J Rheumatol 1994;21:1203-6.

32 Cimmino MA, Seriolo B, Accardo S Influenza vaccination in rheumatoid arthritis. J Rheumatol 1995:22:1802-3.

33 Mitchell LA, Tingle A, MacWilliam L, Horne C, Keown P, Gaur LK, et al. HLA-DR class II associations with rubella vaccine-induced join manifestations. J Infect Dis 1998;177:5-12.

34 Elkayam O, Yaron M, Caspi D. Safety and efficacy of vaccination against hepatitis $B$ in patients with rheumatoid arthritis. Ann Rheum Dis 2002;61:623-5. 